\title{
EDITORIAL
}

\section{CRECIMIENTO POBLACIONAL Y DESARROLLO ECONOMICO}

L

os efectos de un rápido crecimiento poblacional sobre el bienestar económico y social de la población total ha sido objeto de debate durante siglos. En el contexto de la recién finalizada Conferencia Internacional sobre la Población y el Desarrollo celebrada en El Cairo, Egipto del 5 al 13 de septiembre de 1994 dicho debate cobró nuevas fuerzas. El presente editorial tiene como objetivo reflexionar sobre la siguiente interrogante: $¿$ Es el rápido crecimiento poblacional un problema en sí mismo, como muchas personas lo creen, o es la manifestación de otros problemas del subdesarrollo tal como la desigual utilización de los recursos mundiales entre naciones ricas y pobres como lo argumentan otros?

El reverendo Thomas Malthus, en 1798, escribió un ensayo sobre los Principios de la Población. Su estudio se basó en el principio de los rendimientos decrecientes del factor fijo tierra. Con base en dicho principio, Malthus argumentó que la tendencia de la población es crecer a una razón geométrica duplicándose cada 30 o 40 años, a menos que se vea afectada por una hambruna, mientras tanto los alimentos podrían expandirse a una razón aritmética. Las tendencias anteriores conllevarían a que la población se estabilizaría a niveles muy cercanos a la subsistencia. Para evitar lo anterior, Malthus recomendó una práctica mayor de la abstinencia de lo contrario serían los frenos naturales tal como una hambruna la que se encargarían de encontrar el equilibrio entre población y producción alimentaria. Una crítica fundamental al argumento de Malthus ha sido la no adecuada consideración sobre el impacto 
del progreso tecnológico en el aumento de la productividad.

En el presente siglo, los estudios sobre el crecimiento poblacional tienden a incluir en el análisis un conjunto de factores, como el ingreso familiar, beneficios y costos de tener hijos, que un individuo toma en consideración para decidir el tamaño de su familia. En general, una gran parte de la población de los países subdesarrollados consideran que tener muchos hijos se encuentra dentro de su interés económico-social ya que los ven como oferta de trabajo familiar y fuente de soporte financiero cuando los padres sean viejos. Por otra parte, la tradicional marginación de la mayoría de las mujeres en el acceso a la educación y de empleos en los mercados de trabajo formales conllevan a que el costo de oportunidad del tiempo de la madre para criar sus hijos sea relativamente bajo. De tal forma, que sólo en la medida que se vayan ampliando oportunidades de educación y empleos para los pobres y especialmente para las mujeres más un aumento de la cobertura de programas de seguridad social para los ancianos es que se tenderá a sustituir la decisión de cantidad de hijos por calidad de vida de un número menor de hijos para una gran parte de la población de los países subdesarrollados. Y sólo una vez que dicha motivación de tener familias más pequeñas exista, lo cual es vital para reducir las tasas de crecimiento poblacional, los programas de planificación familiar serán una herramienta efectiva.

En cuanto a las consecuencias de altas tasas de fertilidad, por una parte, encontramos tres argumentos principales que consideran que el crecimiento poblacional no es el problema real: (1) la desigual utilización de los recursos entre las naciones ricas y pobres, en un mundo en el cual menos del $25 \%$ de su población que vive en los países desarrollados consumen aproximadamente el $80 \%$ de los recursos a nivel mundial. Por tanto, los países desarrollados deberian prioritariamente cortar sus altos niveles de consumo en lugar de presionar a los países subdesarrollados a que limiten fuertemente su crecimiento poblacional, (2) el número absoluto de personas no es el causante de problemas poblacionales sino su distribución espacial. Por tanto, se deberían implementar medidas que reduzcan los niveles de migración urbano-rural, y (3) el problema se encuentra en la subordinación de la mujer. De forma tal que el limitado acceso a la educación, la falta de oportunidades 
de trabajo; la limitada movilidad social para las mujeres se manifiesta en altas tasas de fertilidad. Por otra parte, tenemos un argumento que considera que el acelerado crecimiento poblacional se encuentra a la base del ciclo población-pobreza. Este argumento se basa en la relación directamente proporcional que mantienen las tasas de crecimiento de ingreso per cápita con respecto a la diferencia entre capital y trabajo. De forma tal, que a mayor tasa de crecimiento de la fuerza de trabajo, la tasa de crecimiento de formación de capital tiene que crecer más rápidamente para mantener los niveles de ingreso per cápita. Lo anterior implica mayores niveles de ahorro e inversión. Con base en lo anterior, se dice que las familias pobres tienen familias más grandes en parte para compensar su pobreza, pero familias más grandes significa un mayor crecimiento poblacional, menores niveles de ahorro e inversión, crecimiento económico más lento, y en última instancia mayor pobreza. Por tanto, se concibe que el crecimiento poblacional es causa y consecuencia del subdesarrollo. El argumento anterior descuida los roles que juegan el cambio tecnológico y las expectativas de venta, entre otros factores, en la relación estudiada, y más particularmente sobre la inversión.

Ahora bien, el largo debate sobre las consecuencias del crecimiento poblacional sobre el bienestar material de la población total ha ido produciendo puntos de consenso importantes. Así la recién finalizada Conferencia sobre Población y Desarrollo celebrada en El Cairo se basó en el considerable consenso internacional logrado desde la Conferencia Mundial de Población celebrada en Bucarest en 1974 y la Conferencia Internacional sobre Población, celebrada en México, D.F., en 1984. Las siguientes cuatro proposiciones constituyen los componentes esenciales del consenso logrado en México: (1) el crecimiento poblacional no es la causa primaria de los bajos niveles de vida y grandes desigualdades que caracterizan a la mayor parte del Tercer Mundo. Las causas fundamentales tienen que buscarse en la naturaleza dual, sectores modernos y tradicionales, de las economías. Así como también en el fracaso de varios programas de desarrollo para crear trabajos e ingreso para los pobres, y muy especialmente para las mujeres, (2) el problema poblacional no es simplemente un problema de números sino de calidad de vida y bienestar material, (3) las altas 
tasas de crecimiento poblacional no son la causa principal del subdesarrollo, sin embargo, constituye un importante factor que contribuye a éste en algunos países y regiones del mundo, y (4) muchos de los problemas de la población surgen no del tamaño total sino de su concentración en áreas urbanas como resultado de una acelerada migración rural-urbana. Un punto más a destacar es el creciente enfásis sobre la marginación de la mujer en el acceso a la educación y oportunidades de empleo.

Los acuerdos aprobados en la Conferencia de El Cairo reflejan la existencia de dichos consensos. A manera de ejemplo nos permitimos hacer las siguientes citas: "Es necesario invertir en el ser humano y comprometerse para que las mujeres tengan los mismos derechos que los hombres" (C.ap. 1, Preámbulo). "Las mujeres deben desempeñar un papel más activo, esencial para reducir el crecimiento demográfico y lograr un desarrollo durable" (Cap. 4, Igualdad para los sexos y refuerzo del poder de las mujeres). "La educación, en especial de la niñas, es un factor clave para el desarrollo" (Cap. 11, Población, desarrollo y educación). "Los problemas de población no pueden ser resueltos si no se aborda el problema de la pobreza" (Cap. 3, Vínculos recíprocos entre población, crecimiento económico apoyado y desarrollo durable). Finalmente, es muy importante destacar el siguiente principio: "La aplicación del Programa debe hacerse según leyes nacionales y respetando los diferentes valores religiosos y éticos de cada pueblo"(Cap.2, Principios). Lo cual es clave para que cada país pueda decidir de acuerdo a sus leyes y principios sobre puntos tan delicados como es el aborto. Los acuerdos aprobados en El Cairo sostienen que el aborto no debe ser alentado como método de planificación familiar, sin embargo, las consecuencias de abortos clandestinos son considerados por primera vez como un problema mayor en materia de salud pública (Cap.8, Salud, mortalidad).

Para finalizar ofrecemos unos lineamientos generales que puedan servir de base para la formulación de políticas en los paises subdesarrollados y desarrollados. Por una parte, los países subdesarrollados pueden seguir tres grandes líneas de políticas: (1) promover programas educacionales para persuadir a la gente para que tengan familias más pequeñas a través de medios formales como las escuelas, informales como la educación para adultos, y 
los medios de comunicación social, (2) esfuerzos para elevar el estatus económico y social de la mujer, especialmente a través de mejorar las oportunidades de educación y empleo para ellas. Así se estarían creando las condiciones para postergar las uniones maritales y el uso de métodos de planificación familiar con lo se reduciría los niveles de fertilidad, y (3) esfuerzos para reducir la migración rural-urbana a través de ir eliminando las enormes diferencias de oportunidades económicas-sociales entre las áreas rurales y urbanas. Todo este esfuerzo debe acompañarse de políticas para la reducción de la pobreza y la desigualdad en la distribución del ingreso. Por otra parte, los países desarrollados deberían cooperar reduciendo sus niveles de consumo, mejorando las relaciones comerciales y de transferencia de tecnología para los países subdesarrollados, y con ayuda financiera para programas de planificación familiar y proyectos de investigación para la elaboración de políticas poblacionales. Estos lineamientos de políticas deben concebirse en una forma integral. Terminamos recordando que los programas de planificación familiar tienen poca utilidad si las personas no se encuentran motivadas para tener familias más pequeñas. Y lo anterior depende del mejoramiento de las condiciones materiales de vida y de las oportunidades de educación y empleo de los pobres, y especialmente de las mujeres. 